\title{
The Dilution of Family Medicine: Waning Numbers of Family Physicians Providing Pediatric Care
}

\author{
Tanya E. Anim, MD, FAAFP
}

(J Am Board Fam Med 2020;33:828-829.)

Family medicine was founded as a specialty in 1969 and pediatric training was an integral part of our training since its inception. ${ }^{1}$

Family physicians continue to comprise the largest percentage of those who identify themselves as primary care physicians in the country. In 2017, $39.5 \%$ of the primary care physician workforce were family physicians, $21.3 \%$ were pediatricians, and $34.5 \%$ were general internal medicine physicians. $^{2}$ This trend is unlikely to change given that $87.1 \%$ of family medicine physicians go on to practice primary care (full scope or not) compared with $12.4 \%$ of internal medicine physicians, and $36.5 \%$ of pediatricians. ${ }^{3}$

Over the years, despite the increased quality of education family physicians receive in training, more and more are narrowing their scope of practice. ${ }^{4}$ This is a clear concern as highlighted by the article by Eden et al, ${ }^{5}$ which demonstrates the continued decline of family physicians caring for pediatric patients. What has led to this change is not entirely clear, but several theories exist. One thought is that as family physicians move from (or are forced out of) maternity care, this has led to dwindling numbers of children who are delivered into our practices. As family physicians we are uniquely qualified to care for the mother, newborn,

This article was externally peer reviewed.

From the FSU College of Medicine Family Medicine Residency Program at Lee Health, Fort Myers, FL.

Funding: None.

Conflict of interest: None.

Corresponding author: Tanya E. Anim, MD, FAAFP, FSU College of Medicine Family Medicine Residency Program at Lee Health, 2780 Cleveland Ave, Suite 709, Fort Myers, FL 33901 (E-mail: Tanya.anim@leehealth.org).

See Related Article on Page 830. and indeed the entire family. Moms who are no longer seeing family physicians for their prenatal care are unaware that we can provide care for their newborns. Rather, they are encouraged by their materniry care provider to find their child a "pediatrician." Although the attrition of family physicians providing maternity care has not been definitively proven in the literature to be a cause of the decline of us providing pediatric care ${ }^{6}$, it may be beneficial for our obstetrician and midwife colleagues to recommend that parents find a pediatrician or talk to their family physician about caring for their newborn. Providing patient education and "preparing for parenthood" literature reflecting this more inclusive language would also be a welcome change.

Another theory, which is linked, but distinctly different is the consideration that as less pediatric patients are seen in our practices and our training sites, residents are graduating with less comfort practicing pediatrics upon graduation. They therefore choose practices that exclude pediatrics or limit the age range of their pediatric patients, electing to see older children only. ${ }^{7}$ In one study, residents descr-ibed that they needed more pediatric exposure to practice pediatrics in their practice going forward, despite being adequately trained as demonstrated by performance on examinations. ${ }^{8}$ As fewer family physicians see younger children, this potentially perpetuates the view of the public that family physician do not or should not care for young children. In addition, there are fewer examples for medical students to see family physicians practicing full-scope family medicine, which may lead to less medical students choosing family medicine. Some may instead elect to choose a career in either pediatrics or internal medicine where they may feel they have more options - to either stay generalists in their fields, or have the option to 
subspecialize later if they so choose. Some may also choose pediatrics and internal medicine combined residency programs, rather than family medicine for that same reason.

Legislative and cost issues are certainly a consideration as contributory factors for the decline, as well. Many practices choose not to care for children due to the low reimbursement rates for caring for pediatric patents, a great proportion of which are on Medicaid, which has been a longstanding issue.

Accepting pediatric Medicaid patients may also be cost prohibitive for many family physicians due to the need to carry vaccines, which is a significant portion of the reason for pediatric clinic visits. The reimbursement rates for the vaccines and the administration of those vaccines, coupled with a lack of adequate pediatric volume to substantiate the cost, is a deterrent to stocking vaccines ${ }^{10}$ for many family medicine practices. Without providing this crucial service, parents are more apt to take their children to practices already with a higher volume of pediatric care. Some may link this issue to the low salary family physicians receive relative to other specialties and the high cost of medical education, but this has not panned out in some studies as a major factor. ${ }^{11}$

The primary care specialties ought to work together to create a shared vision to address the needs of the primary care workforce, including the need for family physicians to continue to provide pediatric care. The challenge presently is that such cooperation may threaten a loss of identity of each specialty. ${ }^{3}$ I personally, am concerned that a continued decline in our scope of care may lead to our specialty appearing to be simply outpatient internal medicine-lacking our distinct focus on broad spectrum, comprehensive care for all ages. Of particular concern is the effect this continued trend will have on rural communities, which may lack pediatricians ${ }^{7}$ leaving many children without adequate care if not cared for by family physicians.

An in-depth look at how to fix these issues is beyond the scope of this commentary. But from personal experience I can tell you that what I do know is that continuing to practice the full scope of the profession is extremely satisfying. In fact, maintaining a broad scope of practice is associated with greater job satisfaction among family physicians and decreases burnout. ${ }^{12}$ As a family medicine educator, I sincerely hope that we strive to continue to keep pediatric care a central and significant portionof our training. I also hope that we continue to serve in areas where we are needed most, for the most vulnerable populations.

To see this article online, please go to: http://jabfm.org/content/ 33/6/828.full.

\section{References}

1. Carek PJ, Anim T, Conry C, et al. Residency training in family medicine: a history of innovation and program support. Fam Med 2017;49:275-81.

2. Petterson SM, Klink K, Meyers D, Bazemore A. The state of primary care in the United States: a chartbook of facts and statistics. 2018. Available from: https://www.graham-center.org/content/dam/rgc/ documents/publications-reports/reports/Primary CareChartbook.pdf.

3. Carney PA, Thayer EK, Green LA, et al. Conditions influencing collaboration among the primary care disciplines as they prepare the future primary care physician workforce. Fam Med 2020;52:398407.

4. Weidner AKH, Chen FM. Changes in preparation and practice patterns among new family physicians. Ann Fam Med 2019;01:46-8.

5. Eden AR, Morgan ZJ, Jetty A, Peterson LE. Proportion of family physicians caring for children is declining. J Am Board Fam Med 2020;33:830-831.

6. Cohen D, Coco A. Trends in well-child visits to family physicians by children younger than 2 years of age. Ann Fam Med 2010;8:245-8.

7. Wasserman RC, Varni SE, Hollander MC, Harder VS. Change in site of children's primary care: a longitudinal population-based analysis. Ann Fam Med 2019;09:390-5.

8. Page C, Carlough MC, Lam Y, Steiner J. Reinvigorating pediatric care in an academic family medicine practice. Fam Med Feb 2014;46: 120-3.

9. Perloff JD, Kletke P, Fossett JW. Which physicians limit their Medicaid participation, and why. Health Serv Res 1995;30:7-26.

10. Campos-Outcalt D, Jeffcott-Pera M, Carter-Smith P, Schoof BK, Young HF. Vaccines provided by family physicians. Ann Fam Med 2010;8:507-10.

11. Alavi M, Ho T, Stisher C, et al. Factors that influence student choice in family medicine-A national focus group. Fam Med 2019;02:143-8.

12. Weidner AKH, Phillips RL, Fang B, Peterson LE. Burnout and scope of practice in new family physicians. Ann Fam Med 2018;05:200-5. 